\title{
Cross Cultural Diversity in Today's Globalized Era
}

\section{Priyameet Kaur Keer Anand}

MBA Department, CMRIT, Bangalore, Karnataka

\section{Email address:}

keerpriyameet@yahoo.co.in

\section{To cite this article:}

Priyameet Kaur Keer Anand. Cross cultural diversity in today's globalized Era. Journal of Human Resource Management. Special Issue: International Human Resource Management. Vol. 2, No. 6-1, 2014, pp. 12-16. doi: 10.11648/j.jhrm.s.2014020601.12

\begin{abstract}
We live in a world with an abundant array of diversity. Diversity is evident in people, the environment, and all forms of life. Advancements in technology have made the world seem smaller and increased the interaction between people from different cultures. The rapid globalisation has a significant impact on the work, employees, and organizations bringing them frequently with clients, suppliers and peer that they never work before. In an era of globalisation, organization faces unique challenges in coordinating among clients, developers, designers' workers from different countries. The major challenges are to develop practices, which balance global competitiveness, multinational flexibility and the building of a worldwide learning capability. This balance will require organisations to develop the cultural sensitivity and ability to manage and leverage learning to build future capabilities. While offering opportunities, globalisation also poses significant challenges to employees especially when different cultures are involved as a team. Multicultural teams have their culture as a set of shared values and beliefs. Beliefs are people's perceptions' of how things are done in their countries. They are reported as "practices" in a particular culture. Values are people's perceptions about the way things should be done. They are their preferred practices and people's beliefs. In a global context the management and development of people inevitably leads to considerations of diversity and related challenges. Attitudes towards working have changed dramatically in recent years and there is currently much more emphasis on multi-cultural working. Many organisations have found that multicultural team integration can be problematic and at times performance is not always at the level required or expected. With an ongoing increase of multicultural teams, leaders in multinational organisations must be aware of cultural diversity issues in order to function effectively and achieve high levels of team performance. This paper will focus on issues like Virtual team, communication in globalized world, resolving conflict and some effective tips for managing cross cultural diversity in the globalized world. Data has been collected from secondary sources.
\end{abstract}

Keywords: Globalization, Multinational Flexibility, Virtual Team, Cultural Diversity, Conflict

\section{Introduction}

The diverse workforce has become a reality today. The impact of cultural diversity varies with the type of environment and firm's overall strategy. Management of cultural differences has become more important for creating advantages and getting competitive edge.

To give a broader definition of the word culture, the word comes in two meanings. The first meaning is "civilization" which entails arts and crafts, education and manners. While the second meaning refers to the way people think, feel and act in accordance with the values and norms dominant in their society. According to Hofstede Geert, culture is defined as "the collective programming of the mind distinguishing the members of one group or category of people from another." In simple words, culture refers to the values known to a certain ethnic group of the same social background.

Work force demographic trends are significant and when combined with an ever more globally focused business community they create a new emphasis on managingdiversity. In this environment business leaders must think more and more about how best to manage a multicultural work force, sell to an increasingly diverse customer base, and deal with suppliers who represent a variety of world views. These tasks are not always easy since diversity is a two edged sword. On the one hand, with diversity come things like an increased numbers of world perspectives and new ways of looking at and attempting to solve problems. If fact, when properly encouraged, a diversity of views can serve to prevent the negative and myopic results of "group think." On the other hand, cultural differences often lead to difficulties with communications and a rise in the friction that can develop as people with different expectations and habits interact. 
Implementing change is always a challenge. People generally find change disconcerting and work to avoid it. In addition, not everyone within an organization values diversity and some may even find it threatening. Given such realities, companies need to go beyond simple recognition of cultural diversity to active diversity management. Diversity management is an inclusive process and should not be viewed as an us/them kind of problem to be solved. Rather, it should be viewed and presented as a valuable resource to be fostered and used. Incorporating a positive and welcoming attitude towards diverse opinions and outlooks usually means making changes to existing practices and habits. But these changes can be explained in such a way as to highlight their value to the organization as a whole and to the ability of staff members to expand their roles.

\section{Culture and Cultural Diversity}

Culture is a broad and comprehensive concept that includes all the ways of being. Culture is learned throughout life as one participates in family and social networks. Cultures have several components, including values and behavioural styles; language and dialects; nonverbal communications; and perspectives, worldviews, and frames of reference. Cultural practices are shared within a specific group and may or may not be shared across groups. It is important to recognize that cultures are always changing because individuals, groups, and the surrounding environment are always changing. Often members of the dominant society or subgroup of a culture view their culture as correct and all others as incorrect or even inferior.

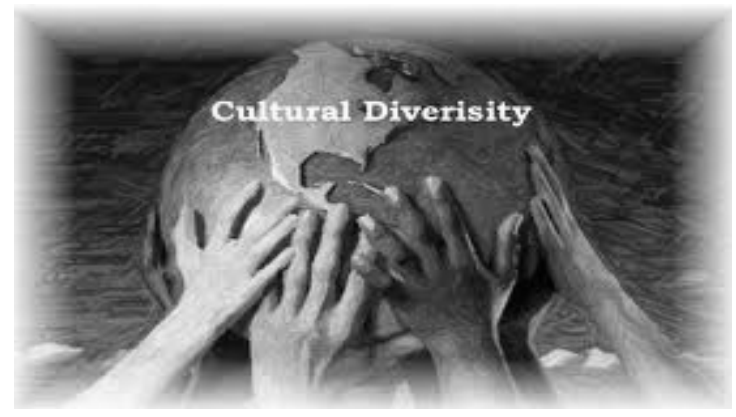

Fig 1. Cultural Diversity

\subsection{Race, Ethnicity, and Racial/Ethnic Diversity, Language and Language Diversity}

Race and ethnicity are often used interchangeably, but they are different. Ethnicity is defined by group membership based on genealogy, national origin, and ancestry. Ethnicity does not change, even though characteristics of a specific ethnic group's culture may change. Language can be defined as a means of communication that shapes cultural and personal identity and socializes one into a cultural group. It is impossible to separate language and culture. One cannot be defined without the other. In order to participate fully in a culture, one must learn that culture's language. Conversely, in order to be fluent in a language, one must learn the culture that language represents.

\subsection{Cross-Cultural Differences in Multi-National Corporations}

Geert Hofstede is a sociologist who studied employees working in a multi-national corporation (Reynolds \&Valentine, 2011). He described four ways that can help in analysing and understanding other cultures as follows:

Individualism vs. Collectivism: In some cultures, the individual is emphasized while in others the group is emphasized.

Power distance: The culture that believes that organizational power should be distributed unequally.

Uncertainty avoidance: Hofstede found that some cultures tend to accept change as a challenge while others don't.

Masculinity vs. Femininity: Hofstede himself tends to reject the terms "masculine" and "feminine".

These two terms should be overlooked in order to value other issues which are more important to the organization such as achievement and assertiveness.

\section{Multicultural Virtual Team Environment}

The most common challenges multicultural virtual teams face in their everyday life and see how to overcome these challenges. Virtual teams work dispersed and share the information and knowledge mainly through the diverse modern communication tools, for example emails, phone calls and teleconferences, whereas the traditional teams have the possibility for information sharing face-to-face.

\subsection{Benefits of a Virtual Team}

The benefits of any form of working are not likely to be highlighted in any research due to the fact that the studies are normally concentrating on giving solutions to problems, not on telling what is already working. One of the main benefits of a virtual team is its flexibility to work across different time zones enabling work task sharing accordingly. The team members often come from different cultural background with not only their specialization, skills and knowledge but also their personal network that can benefit the whole virtual team.

Environmentally speaking remote working creates less gas emission and therefore a smaller carbon footprint. One of the main benefits of a virtual team for the employer is having access to a wider talent pool with no need for relocation.

\subsection{Challenges of a Virtual Team}

Due to rarely happening face-to-face meetings, the challenges of a virtual team are somewhat different of a traditional team. Five challenges to virtual team are as follows:

- Assessment and recognition of virtual team performance

- Building trust within virtual teams 
- Maximizing process gains and minimizing process losses on virtual teams

- Overcoming feelings at isolation and detachment associated with virtual teamwork

- Balancing technical and interpersonal skills among virtual team members

\section{Conflict in a Multicultural Environment}

Culture is a group which shapes a person's values and identity. Cultural conflicts arise because of the differences in values and norms of behavior of people from different cultures. A person acts according to the values and norms of his or her culture; another person holding a different worldview might interpret his or her behavior from an opposite standpoint. This situation creates misunderstanding and can lead to conflict.

\subsection{Identifying Cultural Conflicts}

Cultural conflict has three dimensions. To the two dimensions that every conflict has (content and relational), cultural conflict adds the third one--"a clash of cultural values." This third dimension constitutes the foundation of the conflict since it determines personal identity. Cultural conflict can be identified by the following signs: (1) it usually has complicated dynamics. Cultural differences mentioned above tend to create complex combinations of expectations about one's own and others' behavior. (2) If addressing content and relational issues does not resolve the conflict, it can be rooted in cultural differences. (3) Conflict reoccurs or arises strong emotions even though the issue of disagreement is insignificant.

\subsection{Resolving cultural conflicts}

The resolution of cross-cultural conflict begins with identifying whether cultural issues are involved. There are three ways of cross-cultural conflict resolution.

1. Probing for the cultural dimension.

The resolution process should start from the parties' acknowledgment that their conflict contains a cultural dimension. Next, there should be willingness on all sides to deal with all conflict dimensions including the cultural one. Third, systematic phased work on the conflict is needed. Four phases: (1) the parties describe what they find offensive in each other's behavior; (2) they get an understanding of the other party's cultural perceptions; (3) they learn how the problem would be handled in the culture of the opponent; (4) they develop conflict solutions. Resolution of the conflict is particularly complicated if the conflict arose not just out of misunderstanding of the other's behavior, but because of incompatible values.

2. Learning about other cultures.

People can prevent cross-cultural conflicts by learning about cultures that they come in contact with. This knowledge can be obtained through training programs, general reading, talking to people from different cultures, and learning from past experiences. Important aspects of cultural education are understanding your own culture and developing cultural awareness by acquiring a broad knowledge of values and beliefs of other cultures, rather than looking at them through the prism of cultural stereotypes.

3. Altering organizational practices and procedures.

Often the organizational structure reflects the norms of just one culture and inherits the cultural conflict. In such cases, structural change becomes necessary to make the system more sensitive to cultural norms of other people.

Conflict, depending on the outcome, can be a positive or negative experience for an organization. With changing demographics, cultural differences become an acute issue. Many groups resist assimilation and wish to preserve their cultural distinctiveness, which makes cultural conflict education an essential tool for maintaining healthy relations in organizations and society in general.

\section{Cross - Cultural Communication}

Communication is one of the most important functions to master in order for any business to be successful in today's increasingly competitive markets, particularly for firms doing business internationally. A firm's profitability is in part determined by its business communication strategies and skills. However, top managers in companies working internationally sometimes neglect the significance of the invisible barriers cultural differences create in business communication. Cultural factors play an important role, functioning as invisible barriers.

Culture is an intricate concept, with many different classifications. Simply put, "culture" refers to a group or community with which we share common experiences that shape the way we understand the world. Each of us is shaped by many factors, and culture is one of the powerful forces that influence our lives. Language influences thought and thought influences language, and each is influenced by culture. One may find that people from different cultures may speak the language on different levels of fluency through different gestures, postures etc.

If globalization is an inevitable process, then cross culturalization will also be inevitable. On the one hand, the world is becoming more homogeneous, and distinctions between national markets are fading and, for some products, disappearing altogether. This means that business communication is now a world-encompassing discipline. On the other hand, the cultural differences between nations, regions and ethnic groups, far from being extinguished, are becoming stronger (Lillis and Tian, 2010). This means that global/international business communication, a cross-cultural process, requires managers to be well informed about cultural differences nationally, locally, and ethnically in order to win in global markets. Cross cultural solutions to international business therefore, are increasingly being suggested as a valid and necessary method in enhancing communication and interaction in and between business partners, between 
companies and customers, and between co-workers

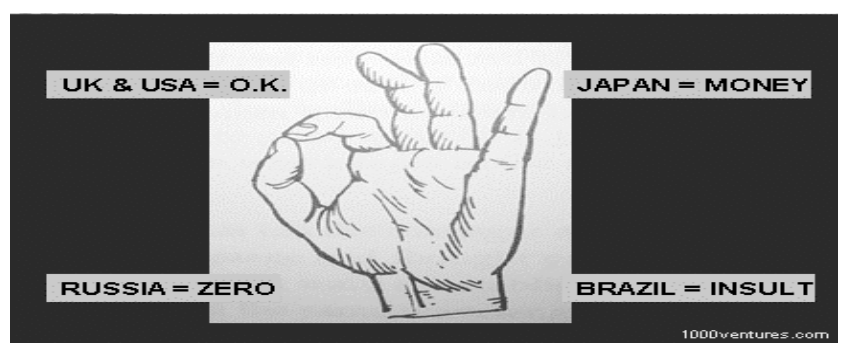

Fig 2. Cross-Cultural Communication

\subsection{Communication (High-Context or Low-Context)}

According to Hall and Hall (1990), they defined the concept "context" which is the surrounding circumstances in which communication occurs. They also made a distinction between high context and low context as follows: A high context (HC) communication or message is one in which most of the information is already in the person, while very little is in the coded, explicit, transmitted part of the message. A low context communication (LC) is just the opposite; i.e., the mass of the information is vested in the explicit code. For example, Japan is considered a high context country because information is implicit in the text while the USA is considered a low context country because the information is given clearly.

The development of intercultural competence is mostly based on the individual's experiences while he or she is communicating with different cultures. When interacting with people from other cultures, the individual experiences certain obstacles that are caused by differences in cultural understanding between two people from different cultures. Such experiences may motivate the individual to acquire skills that can help him to communicate his point of view to an audience belonging to a different cultural ethnicity and background through Fig 3 we can see all three are related and dependent with each other.

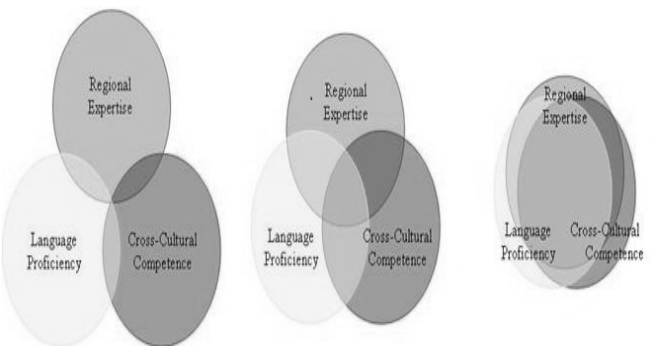

Fig 3. A Framework for the interaction of cross cultural Competence, language proficiency \& Regional Expertise

\section{Effective Management of a Multicultural Work Force}

A company that wishes to encourage diversity and a multiplicity of viewpoints should start by restating the common goals and objectives of the company.

The following items provides a checklist for implementing policies that will foster and encourage a harmonious, multicultural work force.

- Start at the top - A commitment to the idea of an open and receptive work place must be seen from the owners and managers of a company early on, preferably before official policies are announced.

- Communicate in writing-Company policies that explicitly forbid prejudice and discriminatory behaviour should be included in employee manuals, mission statements, and other written communications. This has been referred to by some as a way of broadcasting the diversity message internally in order to create a common language for all members of the organization.

- Training programs - Training programs designed to engender appreciation and knowledge of the characteristics and benefits of multicultural work forces have become ubiquitous in recent years. Two types of training are most popular: awareness and skill-building. The former introduces the topic of managing diversity and generally includes information on work force demographics, the meaning of diversity, and exercises to get participants thinking about relevant issues and raising their own self-awareness. The skill-building training provides more specific information on cultural norms of different groups and how they may affect communications and behaviour.

- Recognize individual differences - Do not make the mistake of assuming that differences are always 'cultural.' There are several sources of difference. Some relate personality, aptitude, or competence. This sort of differences is more likely to reflect bias and intellectual laziness than it does culturally to sensitive managers.

- Actively seek input from minority groups - Soliciting the opinions and involvement of minority groups on important work committees, etc., is beneficial not only because of the contributions that they can make, but also because such overtures confirm that they are valued by the company. Serving on relevant committees and task forces can increase their feelings of belonging to the organization. Conversely, relegating minority members to superfluous committees or projects can trigger a downward spiral in relations between different cultural groups.

- Revamp reward systems-An organization's performance appraisal and reward systems should reinforce the importance of effective diversity management. This includes assuring that minorities are provided with adequate opportunities for career development.

- Flexible work environment-Flexible work environments may have particularly beneficial results with people from non traditional cultural backgrounds because their approaches to problems are more likely to be different from past norms.

- Continuous monitoring-Experts recommend that business owners and managers establish and maintain systems that can continually monitor the organization's 
policies and practices to ensure that it continues to be a good environment for all employees. Be flexible and apply the lessons learned as new situations arise and are managed.

\section{Conclusion}

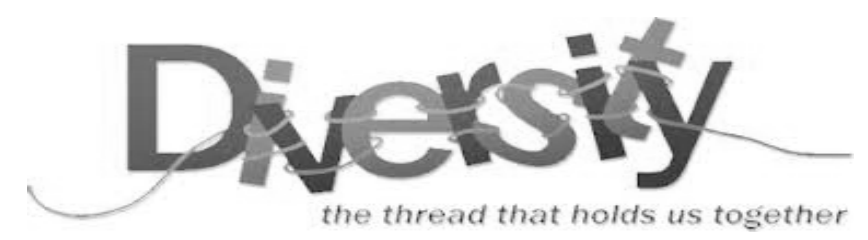

Increased diversity may present a challenge to business leaders who must work to maximize the opportunities that diversity provides while minimizing its costs. The organization that achieves this objective will create an environment in which all employees are able to contribute to their fullest potential, and in which the 'value in diversity' can be fully realized. In many ways, cultural diversity in the work place mirrors many of the same issues at play in the realm of international business. Cultural norms shift relative to language, technological expectations, social organization, face-saving, authority conception, nonverbal behaviour and the perception of time. Managing diversity is a comprehensive process for developing an environment that works for all employees. . It is important, consequently, for an organization to create an environment in which the positives of diversity are harnessed and the negatives are minimized as much as possible.

\section{References}

[1] Berta, Dina. "MFHA Confab: Straight Talk on Workplace Diversity." Nation's Restaurant News. 17 October 2005.

[2] Albert, D. R. (1996). A Framework and Model for Understanding Latin American and Latino American and Laino/Hispanic Cultural Patterns. In Landis, D. and Bhagat R.S. (Eds). Handbook of Intercultural Training, $2^{\text {nd }}$ edition. U.S.A.: Sage Publications.

[3] Bennett, J, M. and Bennett, M. J. (2004). Developing Intercultural Sensitivity: An Integrative Approach to Global and Domestic Diversity. In Landis, D., Bennett, J. M., and Bennett, M. J. (Eds) Handbook of Intercultural Training, $3^{\text {rd }}$ ed.,). Thousand Oaks, CA: Sage, 147-165.

[4] Lustig, M. W. and Koester, J. (2006). Intercultural competence: Interpersonal communication across cultures. Boston MA: Pearson Education.

[5] Marshall, P.L. (2002). Cultural diversity in our schools. Belmont: Wadsworth.

[6] Martin, J.N. and Nakayama, T. K. (2000). Intercultural Communication in Contexts, $2^{\text {nd }}$ ed. California. Mayfield Publishing Company.

[7] Tian Guang and Dan Trotter, Key issues in cross-cultural business communication:Anthropological approaches to international business, Shantou University, Shantou City, Guangdong Province, Southern China 